\title{
The effect of the Bain circuit on gas exchange
}

This is an experimental and theoretical analysis of the Mapleson $D$ (Bain) circuit. A bench model was used to determine the effects of breathing rate, tidal volume, and fresh gas flow on the simulated alveolar gas composition when a commercial Bain breathing circuit is used. In addition, an effort was made to derive mathematical equations that describe the $\mathrm{CO}_{2}$-profile in the expiratory limb of the Bain circuit, the amoun of $\mathrm{CO}_{2}$ rebreathed, and the effect of this rebreathing on the alveolar gas composition. Data obtained with the bench model and with the equations were compared to data from the literature. The effect of the Bain circuit on gas exchange was compared to that of an equivalent dead space.

Several valveless breathing circuits have been introduced into anaesthetic practice. ${ }^{1}$ The Bain circuit, ${ }^{2}$ a modification of the Mapleson circuit (Type D) is being sold in millions of disposable units. This popularity derives from the simplicity of the circuit, which consists of a single tube that is attached to the patient with an elbow connector. Fresh gas is supplied through a narrow conduit that runs within the tube. The circuit is used during mechanical or spontaneous ventilation.

It has been known since their introduction that valveless breathing circuits cause some rebreathing when the inspiratory flow rate exceeds the rate of fresh gas supply. The patient's arterial $\mathrm{PCO}_{2}$ is, therefore, higher than with breathing systems that prevent rebreathing at the same minute ventilation. ${ }^{2}$ One problem inherent to valveless systems is the difficulty in predicting the amount of rebreathing; several studies have evaluated this problem in animals and humans. ${ }^{3}$ When to use the system and how

\section{Key words}

ANAESTHETIC BREATHING CIRCUIT: valveless breathing circuit, Bain circuit, dead space; RESTIRATORY GAS EXCHANGE: rebreathing, dead space.

From the Departments of Physiology and Anesthesiology, University of Florida College of Medicine, Gainesville, Florida.

Address correspondence to: Dr. Marc Jaeger, Department of Physiology, Box J-274, J. Hillis Miller Health Center, Gainesville, Florida 32610-0274. to adjust such variables as fresh gas flow, frequency, tidal volume, and breathing pattern is still controversial.

This paper presents a theoretical analysis of the Bain circuit, which elaborates on work by Mapleson ${ }^{4}$ and compares computed results with bench model experiments and with data from the literature. We evaluate the effect of the Bain circuit on a subject by accounting for all $\mathrm{CO}_{2}$ eliminated and rebreathed. The procedure leads to equations which show which respiratory variables determine the effect of the Bain circuit and how they interact. It

\section{Abbreviations and symbols}

f bpm or bps

breathing rate. For dimensional uniformity used often as bps.

$V_{T} \quad L$ tidal volume of subject.

$V_{T^{\prime}} \quad \mathrm{L} \quad$ tidal volume read off ventilator.

FGF $L \cdot \min ^{-1}$ or $\mathrm{L} \cdot \mathrm{sec}^{-1}$ fresh gas flow.

$T_{i}, T_{\mathrm{t}} \sec \quad$ inspiration, expiration

$\dot{V}_{i}, \dot{V}_{e} L \cdot \sec ^{-1}$ time.

instantaneous flow in airways.

$\dot{V}_{i}^{\prime}, \dot{V}_{e}^{\prime} L \cdot \sec ^{-1}$

VDarr

VDb

instantaneous flow in expired limb.

anatomical dead space.

functional dead space of Bain circuit.

$V_{\text {Dan' }}$

$\mathrm{FACO}_{2}$

anatomical dead space corrected for FG dilution.

$\mathrm{CO}_{2}$ fraction in alveoli, assumed to be constant at steady state.

$\mathrm{FBCO}_{2}$

$\mathrm{CO}_{2}$ fraction in the gas that enters the expired $\operatorname{limb}$; it is a dilution of expired gas with $\mathrm{FG}$.

$\mathrm{CO}_{2}$ rebreathed

amount of $\mathrm{CO}_{2}(\mathrm{ml})$ that enters the airway per breath.

$\mathrm{CO}_{2}$ load enters the al veolar space per breath and affects $\mathrm{PCO}_{2}$. 
is found that the Bain circuit can be compared to an added dead space which affects ventilation like an instrumental dead space. This added dead space varies with the subject's breathing, but does not vary with his $\mathrm{CO}_{2}$ production ( $\left(\mathrm{VCO}_{2}\right)$ nor with his alveolar $\mathrm{PCO}_{2}\left(\mathrm{PACO}_{2}\right)$. These findings are documented with bench model experiments and clinical applications are discussed.

\section{Methods}

The model, similar to one described by Rose et al., consists in principle of a piston in a cylinder, which represents the lung, connected to a tube, which represents the anatomical dead space, VDan (Figure 1a). VDan is kept constant in our setup. This mechanical lung and trachea is attached to a $\mathrm{T}$-shaped connector with inflow and outflow tubes, which are flushed with fresh gas at a given flow rate (FGF). Carbon dioxide production is simulated by infusing $\mathrm{CO}_{2}$ into the cylinder at a constant, calibrated rate $\left(\dot{\mathrm{V} C \mathrm{CO}_{2}}=0.260 \mathrm{~L} \cdot \mathrm{min}^{-1}\right.$ ).

For the bench experiments, one lung of a bellows-type dual test lung (Vent-Aid ${ }^{\mathbb{}}$, Michigan Instruments, Grand Rapids, Michigan) was used. A fan inside the lung generated a homogeneous alveolas gas composition. A large bore Tygon tube ( $2 \mathrm{~cm}$ ID) connected to the lung served as an "airway" and was intubated with a cuffed, 7.5-mm endotracheal tube. The total anatomic dead space (VDan) (Tygon plus endotracheal tube) was $125 \mathrm{ml}$, as measured by water displacement. The volume of the test lung is $1.5 \mathrm{~L}$. The alveolar $\mathrm{CO}_{2}$ fraction $\left(\mathrm{FACO}_{2}\right)$ was sampled inside the test lung and measured with a Godart Type 17070 infrared capnograph, which was calibrated with standard gas mixtures. A strip chart recorder (Grass, Model 7B) provided a permanent record of $\mathrm{FACO}_{2}$, which was reproducible within $\pm 0.002 \mathrm{ml} \mathrm{CO}_{2} / \mathrm{ml}$ air. Tidal volume was measured with a rotational transducer (Harvard Apparatus) attached to the hinge of the test lung. Tidal volume was also recorded on the chart and was reproducible and accurate within $\pm 25 \mathrm{ml}$.

The trachea of the lung model was connected by a standard elbow to a commercial Bain circuit and to an Ohio Modulus anaesthesia machine (Ohio Medical Products, Madison, Wisconsin). Ventilation was provided either by an Ohio 7000 electronic ventilator or by a sinusoidal pump. In the first instance, the flow tracing was a square wave during inspiration and followed an exponential decline during expiration. In the second instance, the flow pattern was sinusoidal.

To calculate alveolar ventilation $\left(\dot{\mathrm{V}}_{\mathrm{A}}\right)$, the alveolar gas equation $\left(\dot{\mathrm{V}}_{\mathrm{A}}=\dot{\mathrm{V}} \mathrm{CO}_{2} / \mathrm{FCO}_{2}\right)$ was modified to account for the $\mathrm{CO}_{2}$ lost during capnograph sampling: $\dot{\mathrm{V}}_{\mathrm{A}}=$ $\left(\dot{\mathrm{V}} \mathrm{CO}_{2}-\dot{\mathrm{V}}_{\mathrm{s}} \mathrm{FACO}_{2}\right) / \mathrm{FACO}_{2}$, where $\dot{\mathrm{V}}_{\mathrm{s}}$ is the sampling rate. In order to account for all the $\mathrm{CO}_{2}$ being eliminated, this loss has to be accounted for. It varies with the

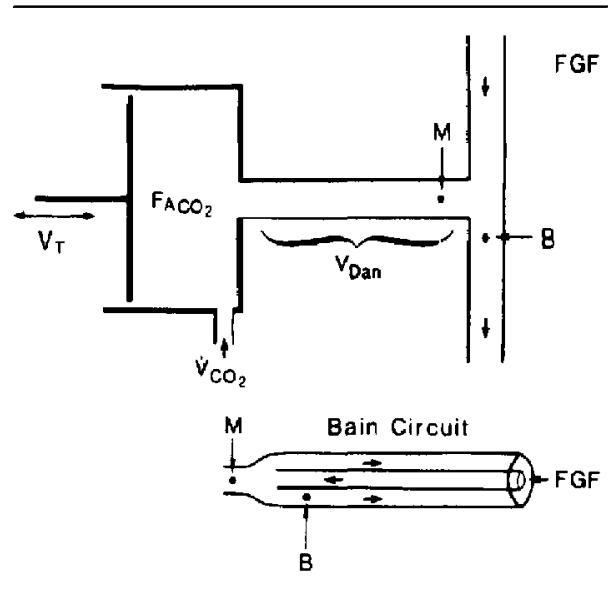

FIGURE 1 Schematic of the model used to scudy gas exchange in the Bain circuit. The upper panel describes the simplified model used for computation. The lower panel gives a diagram of the Bain circuit For bench model experiments this circuit would be added to the anatomical dead space VDan so as to have the letters $M$ ("mouth") coincide.

experimental conditions and may be fairly large when $\mathrm{FACO}_{2}$ is high. For all experiments $\dot{\mathrm{V}}_{s}$ was adjusted to equal $\mathrm{VCO}_{2}$ to simulate a respiratory exchange ratio of unity. Measurements were conducted at three levels of FGF $\left(3.5,7\right.$, and $\left.14 \mathrm{~L} \cdot \mathrm{min}^{-1}\right)$, at four frequencies $(5,10$, 15 , and 20 breaths $\left.\cdot \min ^{-1}\right)$, and at four levels of tidal volume Vr $(0.4,0.75,1.0$ and $1.5 \mathrm{~L})$. Lung compliance of the test lung was adjusted to $0.1 \mathrm{~L} \cdot \mathrm{cm} \mathrm{H}_{2} \mathrm{O}^{-1}$. We assumed that the gas in the bench model was dry and $\mathrm{PCO}_{2}$ was therefore computed for ATPD conditions. Statistical evaluations were done using a paired $t$-test, with a significance level of $p<0.05$.

\section{Theory}

The computation of a patient's $\mathrm{PACO}_{2}$ when connected to a valveless breathing circuit, is based on the gas mixing in the circuit. ${ }^{4}$ We assume that the gas flow in the airways follows some mathematically defined time course, such as a square wave or an exponential wave, and mixes with the fresh gas which has a constant rate. The mixing pattern allows us to predict the $\mathrm{CO}_{2}$ concentration in the expired limb of the Bain circuit and the amount of $\mathrm{CO}_{2}$ bcing rebreathed in the next breath. The rebreathing is expressed as the functional dead space of the Bain circuit (VDb) which is added to the patient's own anatomical dead space ( $V_{\text {Dan }}$ ). The patient's alveolar $\mathrm{PCO}_{2}$ is then derived with the standard alveolar gas equation. The computations are detailed in the Appendix. 
When a subject is connected with a Bain circuit to a ventilator, the subject's tidal volume VT is larger than the tidal volume $V_{T^{\prime}}$ read off the ventilator since fresh gas enters the system between subject and ventilator. The inspired tidal volume $V_{I}$ is made up of fresh gas and of $\mathrm{VT}^{\prime}$ which comes from the expired limb and contains $\mathrm{CO}_{2}$. This $\mathrm{CO}_{2}$ is rebreathed and its amount needs to be evaluated. The gas mixing may be illustrated with an example.

Let us assume that the inspiratory gas flow $\left(\dot{V}_{i}\right)$ is constant while the expiratory gas flow $\left(\dot{V}_{e}\right)$ follows an exponential pattern. For numerical illustration we ussume that the breathing rate (f) is $10 \mathrm{bpm}, \mathrm{V}_{\mathrm{I}}$ is $0.75 \mathrm{~L}$ and that the $I: E$ ratio is $1: 2$. The inspiratory time $\left(T_{i}\right)$ then is $2 \mathrm{sec}$ and expiratory time $T_{c}$ is $4 \mathrm{sec}$. Expiratory flow rises rapidly to a maximum $\left(0.65 \mathrm{~L} \cdot \mathrm{sec}^{-1}\right)$ and then declines exponentially to zero.

The respiratory and the fresh gas flows add or subtract in the Bain circuit: the flow in the expiratory limb of the Bain circuit (site $B$ in Figure 1) equals $\dot{V}_{e}+F G F$ during expiration and $\dot{V}_{i}-F G F$ during inspiration. Similarly, the volume of gas entering the Bain circuit during expiration is larger $\left(V_{T}+F G F \times T_{e}\right)$ than the volume of gas rebreathed by the patient (VT $-F G F \times T_{i}$ ). Using the numerical values given earlier, the volume of gas entering the circuit at site B equals $1.21 \mathrm{~L}$, while the volume rebreathed ( $\mathrm{Yr}^{\prime}$ ) is only $0.52 \mathrm{~L}$ if $\mathrm{FGF}=7 \mathrm{~L} \cdot \mathrm{min}^{-1}$. Keeping this in mind we may compute the instantaneous mixing of gas and the resulting $\mathrm{CO}_{2}$-profile in the circuit.

We assume, for simplicity, that expired gas has alveolar composition. This simplifying assumption will be justified later. Setting the $\mathrm{CO}_{2}$ concentration of expired gas equal to $\mathrm{FACO}_{2}$, we compute the dilution of expired gas with fresh gas as

$\mathrm{FBCO}_{2}=\mathrm{F}_{\mathrm{A}} \mathrm{CO}_{2} \cdot \dot{\mathrm{V}}_{\mathrm{e}} /\left(\dot{\mathrm{V}}_{\mathbf{e}}+\mathrm{FGF}\right)$

(Equation 1)

where $\mathrm{FBCO}_{2}$ is the instantaneous concentration of $\mathrm{CO}_{2}$ at site $\mathrm{B}$ (Figure 1). This gas moves downstream into the expiratory limb. At the end of expiration the $\mathrm{CO}_{2}$ concentration in the expiratory limb has the profile shown in Figure $2 \mathrm{~b}$. The concentration is low at the proximal end of the tube, since endexpiratory flow is low. At the distal end, however (right side of the diagram in Figure 2b), the concentration is high and close to alveolar composition since early expiratory flow is high $\left(\dot{V}_{\mathrm{e}}=0.65 \mathrm{~L} \cdot \mathrm{sec}^{-1}\right)$ compared to fresh gas flow (FGF $\left.=0.116 \mathrm{~L} \cdot \mathrm{sec}^{-1}\right)$. The abscissa is the volume of gas which has entered the tube. It equals, as mentioned, $1.21 \mathrm{~L}$. The area under the curve represents the amount of $\mathrm{CO}_{2}$ (in ml) that has entered the circuit. This area allows us to assess how much $\mathrm{CO}_{2}$ is reinspired by the subject during the following inspiration: if we mark on the abscissa the volume rebreathed $\mathrm{VT}^{\prime}=$ $0.52 \mathrm{~L}$, the area under the curve up to that volume defines

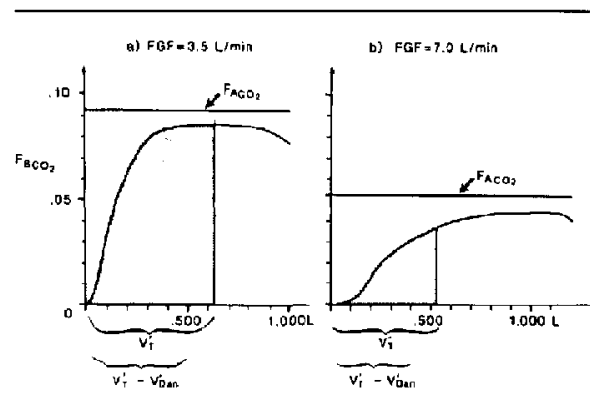

FIGURE $2 \mathrm{CO}_{2^{-}}$profile in the expiratory limb of the Bain circuit computed for two levels of FGF. $\mathrm{FBCO}$ on the ordinate is the fraction at any site of the Bain circuit. The amount of gas expelled into the Bain circuit and diluted with FG is plotted on the abscissa (V). From that volume an aliquot $\left(\mathrm{VT}^{\prime}\right)$ is rebreathed. The shaded area is the $\mathrm{CO}_{2}$ rebreathed. The shaded area up to VT' - Vhar' is the metabolic $\mathrm{CO}_{2}$ load.

the volume of $\mathrm{CO}_{2}$ rebreathed (Figure $2 b$, shaded area). This is the $\mathrm{CO}_{2}$ rebreathed by the subject as measured at the airway opening and amounts to $10.7 \mathrm{ml}$ in our example.

Figure 2 allows us to justify the earlier assumption that expired gas has alveolar composition. Only a relatively small portion of the gas in the Bain circuit $(0.52$ out of $1.21 \mathrm{~L}$ ) is rebreathed. Even though that portion may be higher under conditions other than those chosen in our example, the distal portion of the Bain expirate, which contains the gas from the subject's anatomical dead space, is hardly ever rebreathed. Thus, knowledge of its composition is not required to compute the $\mathrm{CO}_{2}$ rebreathed. It should also be noted that not all the $\mathrm{CO}_{2}$ rebreathed reaches the subject's alveolar space. Some of the $\mathrm{CO}_{2}$ remains in the anatomical dead space and is expelled again in the next expiration. The shaded area in Figure 2 therefore overestimates the effect of tebreathing on gas exchange, since only the $\mathrm{CO}_{2}$ that reaches the alveolar space can influence the subject's gas exchange. This portion is smaller than the shaded area and can be determined as outlined in the appendix. It is approximately equal to the area in Figure 2 up to a volume equal to $\mathrm{VT}^{\prime}$ $(0.52 \mathrm{~L})$ minus a portion of VDan. This reduced area $\left(\mathrm{CO}_{2}-\mathrm{load}\right)$ is approximately equal to $6.9 \mathrm{ml}$.

Figure 2 also illustrates the effect of $\mathrm{FGF}$ on the $\mathrm{CO}_{2}$ profile and on rebreathing. If $F G F$ is reduced from $7 \mathrm{~L} \cdot \mathrm{min}^{-1}$ to $3.5 \mathrm{~L} \cdot \mathrm{min}^{-1}$ (Figure $2 \mathrm{a}$ ), the $\mathrm{CO}_{2}$ concentration is much higher. In addition, the amount of gas rebreathed $\left(V_{T}^{\prime}=V T-F G F \times T_{i}\right)$ increases from 0.52 to $0.63 \mathrm{~L}$. The shaded area is, therefore, much larger and the $\mathrm{CO}_{2}$ load reaches $31.6 \mathrm{ml}$ instead of $6.9 \mathrm{ml}$.

We can now assess the effect of $\mathrm{CO}_{2}$ rebreathing on 


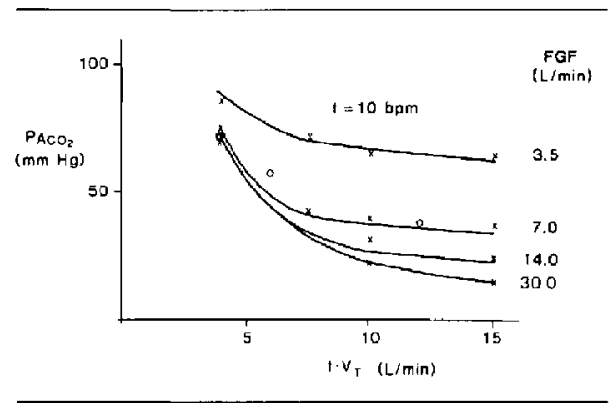

FIGURE $3 \quad \mathrm{PACO}_{2}$ measured in the bench model (crosses) is plotted agains! minute volume (fVT). The frequency is kept constant (f = $10 \mathrm{bpm}$ ) and only $V_{T}$ is varied. Inspiration is a square wave, expiration has an exponential time course. Results at various levels of FGF are indicated. The lines are compuled. Statistical analysis (paired ttest, $p>0.05$ ) showed no significant difference between bench model and computations. The circles are from reference 5. Figure 3, corrected for the higher $\mathrm{VCO}_{2}$ in our experiment.

alveolar and blood gases using the concept of functional dead space. Any $\mathrm{CO}_{2}$ load can be expressed in terms of the equipment dead space that would result in the same $\mathrm{CO}_{2}$ load. By standard definition the $\mathrm{CO}_{2}$ load equals the equipment dead space times $\mathrm{FACO}_{2}$. Thus, the functional dead space of the Bain circuit (VDb) equals the $\mathrm{CO}_{2}$ load (shaded area in Figure 2) divided by $\mathrm{FACO}_{2}$. The mathematical derivation outlined in the appendix shows that, with this approach, $\mathrm{FACO}_{2}$ drops out of the equation since it appears in the numerator and denominator. This means that the functional dead space of the Bain circuit is independent of alveolar gas composition.

Having computed $\mathrm{VDb}$, the effect of the Bain circuit on gas exchange is evaluated with the standard alveolar gas equation:

$\mathrm{PACO}_{2}=(760) \dot{Y} \mathrm{CO}_{2} /\left(V_{T}-V_{D a n}-V_{D b}\right) f$

(Equation 2)

This equation assumes that all gases in the bench model are at ambient pressure and dry. For use with patients the equation is modified in the standard fashion with the numerator in STPD and the denominator in BTPS conditions.

\section{Results}

The $\mathrm{PACO}_{2}$ was computed for a number of assumed conditions and compared with the data obtained from bench model experiments where $\mathrm{FACO}_{2}$ is measured directly. FGF, VT, and $f$ were varied independently over a wide range. The breathing pattern assumed, in the first series of experiments, a constant inspiratory flow followed by an exponential expiration with an inspiratory to

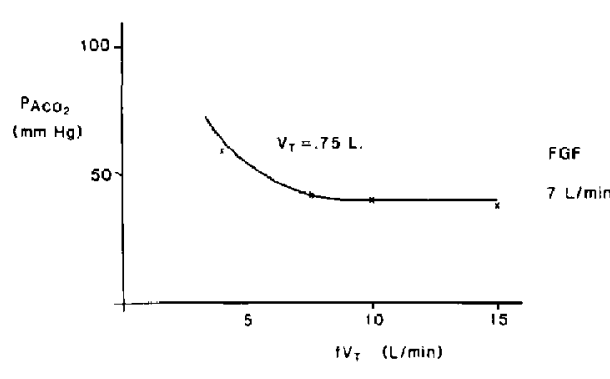

FIGURE $4 \quad \mathrm{PACO}_{2}$ measured in the bench model (crosses) is plotted as in Figure 3 against $\mathrm{fVT}$; $\mathrm{VT}$ is kept constant at $0.75 \mathrm{~L}$. Linc is computed. Flow pattem as in Figure 3.

expiratory ratio of $1: 2$. The theory and model experiment correlate strongly: Figure 3 shows that $\mathrm{PCO}_{2}$ declines in a curvilinear fashion when $V_{T}$ is raised while other variables are kept constant; the decline of computed values (continuous lines) follows closely the experimental data (crosses). The differences between measured values and the computed data for the same conditions are not statistically significant ( $t-t e s t ; p>0.05$ ). The observation holds true at four levels of FGF. When FGF is raised, while other variables are constant, $\mathrm{PACO}_{2}$ also declines in a non-linear fashion: An increase of FGF from 3.5 to 7.0 $\mathrm{L} \cdot \mathrm{min}^{-1}$ may result in a fall of $\mathrm{PACO}_{2}$ by $30 \mathrm{mmHg}$. The increase of FGF from 7 to $14 \mathrm{~L} \cdot \mathrm{min}^{-1}$, however, results in a fall of $\mathrm{PACO}_{2}$ by only $12 \mathrm{mmHg}$.

Figure 4 shows that frequency has an independent effect on $\mathrm{PACO}_{2}$. When $f$ is raised while other variables are kept constant, $\mathrm{PACO}_{2}$ falls and then lcvels off. Theory and experiments again agree well.

For a second series of experiments a breathing pattern simulating a sine wave was used. The compuced data follow lines which have the same curvilinear shape as the lines shown in. Figure 3 but are 6 to $10 \mathrm{mmHg}$ higher than the lines obtained for the square/exponential wave form. The data are not shown for brevity. The data obtained on the bench model again follow the theory closely (t-test; $p>0.05$ )

In a third series of experiments we examined the effect of $\mathrm{VCO}_{2}$ on $\mathrm{FACO}_{2}$ when other variables were kept constant. When $\mathrm{VCO}_{2}$ was raised in four steps from $62.5 \mathrm{ml} \cdot \mathrm{min}^{-1}$ to $425 \mathrm{ml} \cdot \mathrm{min}^{-1}, \mathrm{FACO}_{2}$ increased linearly. The experiment was repeated three times with different settings of FGF. There was each time an excellent linear relationship. The overall correlation coefficient of 11 measurcments was 0.994 .

The Table lists a number of results which allow us to evaluate the effect of additional factors on gas exchange. 
TABLE Comparison of gas cxchange during different breathing patterns with the Bain circuit.

\begin{tabular}{|c|c|c|c|c|c|c|c|c|c|}
\hline Condition & $\begin{array}{l}f \\
b p m\end{array}$ & $\begin{array}{l}V_{T} \\
L\end{array}$ & $\begin{array}{l}F G F \\
L \cdot \min ^{-1}\end{array}$ & Flow pattern & I:E & $\begin{array}{l}V_{T^{\prime}} \\
L\end{array}$ & $\begin{array}{l}V D b \\
L\end{array}$ & $\begin{array}{l}\mathrm{PACO}_{2} \\
\mathrm{mmHy}\end{array}$ & $\begin{array}{l}\mathrm{CO}_{2} \text { load } \\
\mathrm{ml}\end{array}$ \\
\hline 1 & 10 & 0.4 & 7 & sq/exp ${ }^{*}$ & $1: 2$ & 0.168 & 0.003 & 72.6 & 0 \\
\hline 2 & 10 & 0.75 & 7 & sq/exp* & $1: 2$ & 0.518 & 0.132 & 40.0 & 6.9 \\
\hline 3 & 20 & 0.4 & 7 & sq/exp ${ }^{*}$ & $1: 2$ & 0.284 & 0.095 & 54.9 & 6.8 \\
\hline 4 & 40 & 0.4 & 7 & sq/exp* & $1: 2$ & 0.342 & 0.178 & 50.9 & 11.9 \\
\hline 5 & 10 & 0.4 & 7 & sine & $1: 2$ & 0.195 & 0.012 & 75.1 & 1.2 \\
\hline 6 & 10 & 0.75 & 7 & sine & $1: 2$ & 0.532 & 0.231 & 50.1 & 15.2 \\
\hline 7 & 10 & 0.75 & 7 & sine & $1: 1$ & 0.436 & 0.217 & 48.4 & 13.8 \\
\hline 8 & 10 & 0.75 & 3.5 & sqiexp & $1: 2$ & 0.634 & 0.343 & 70.1 & 31.6 \\
\hline 9 & 40 & 0.4 & 3.5 & sq/exp & $1: 2$ & 0.284 & 0.223 & 95.0 & 27.9 \\
\hline
\end{tabular}

*sqiexp = flow during inspiration is constant producing a square pattem; during expiration flow declines exponentially (Equation 12)

It lists the volume of gas rebreathed from the Bain circuit $\left(\mathrm{VT}^{\prime}\right)$, the functional dead space of this circuit $(\mathrm{VDr})$ and the $\mathrm{CO}_{2}$-load under various conditions. The increase of VT from 0.4 to $0.75 \mathrm{~L}, \mathrm{e.g}$, , results in an increase of the functional dead space from 0.003 to $0.132 \mathrm{~L}$ and an increase of the $\mathrm{CO}_{2}$-load from 0 to $6.9 \mathrm{ml}$ (lines $\mathrm{l}$ and 2). A doubling of respiratory rate from 20 to $40 \mathrm{bpm}$ augments the $\mathrm{CO}_{2}$-load from 6.8 to $11.9 \mathrm{ml}$ per breath, yet results in a small decline of $\mathrm{PACO}_{2}$ (lines 3 and 4 ). An increase of the breathing rate from 10 to $20 \mathrm{bpm}$ with concomitant reduction of $V_{T}$ so as to keep minute volume constant does not affect the $\mathrm{CO}_{2}$-load yet causes a substantial increase in $\mathrm{PACO}_{2}$ (lines 2 and 3 ). The change of breathing pattern from square inspiration/passive, exponential expiration to a pure sine wave causes, as mentioned earlier, an increase of $\mathrm{PACO}_{2}$ (compare lines 2 and 6). A change of the $I: E$ ratio from $1: 2$ to $1: 1$ is without significant effect on gas exchange.

\section{Discussion}

We assumed for our theoretical computations that fresh gas enters the system at the mouth and that instantaneous and complcte mixing takes place at the site of gas entry. We also assumed that the Bain circuit consists of a long tube with a volume larger than the volume of gas rebreathed from the circuit $\left(\mathrm{Vr}^{\prime}\right)$ and that no mixing takes place in the tube so that the $\mathrm{CO}_{2}$-profile (Figure 2), once established, remains unchanged, at least for the duration of inspiration. The breathing pattern is assumed to follow a mathematical function. The pop-off valve is assumed to be situated far downstream (beyond $\mathrm{VT}^{\prime}$ ) and its timing to be without effect on the breathing pattern and mixing. None of these assumptions is completely true. The fow pattern generated by a commercial ventilator connected to an intubated patient is outlined only in its main features by the simplified mathematical function used. The corrugated tube is expected to provide some mixing within the Bain circuit and recent findings document that mixing does not take place instantaneously at the site of fresh gas entry. ${ }^{7}$ It is interesting that despite these shortcomings, the mathematical model correlates well with the experimental findings (Figures 3 and 4). Apparently, the simplifications do not appreciably reduce the validity of the theory.

Our computed results correlate also with experimental data from a previous study of gas exchange in a bench model (Figure 3, circles). ${ }^{5}$ To compare these data with those of Figure 3, we multiplied Rose's data by $0.26 / 0.18$ to account for the fact that our $\mathrm{VCO}_{2}$ was higher than the one used by Rose et al. The rationale for this adjustment is based on the finding that $\mathrm{FACO}_{2}$ is proportional to $\mathrm{VCO}_{2}$ (results, third series).

In order to compare the theory with the clinical measurements by Bain and Spoerel, ${ }^{3}$ the data are redrawn using as coordinates $\mathrm{PACO}_{2}$ and $\mathrm{FGF}$ (Figure 5); ventilation is expressed as the product of frequency times set volume $\mathrm{VT}^{r}$. The agreement between clinical data and computed results is acceptable. The slope of the clinical data is lower than the slope of the computed isoventilation lines, presumably because the ventilation rate $\left(\mathrm{fVT}^{\prime}\right)$ of the patients increased when FGF was low. Thus, the patients' data may be expected to move from an isoventilation line of $\mathrm{fV}_{\mathrm{T}^{\prime}}=5 \mathrm{~L} \cdot \mathrm{min}^{-1}$ at $\mathrm{FGF}=7 \mathrm{~L} \cdot \mathrm{min}^{-1}$ to an isoventilation line of $10 \mathrm{~L} \cdot \mathrm{min}^{-1}$ at a FGF of $3.5 \mathrm{~L} \cdot \mathrm{min}^{-1}$.

The main reason for the good agreement between theory and experiment is probably the fact that only the proximal section of the Bain circuit is relevant for the gas exchange. That section contains the gas which, upon rebreathing, reaches the alveolar space. More distally located gas does not contribute to the gas exchange and its composition and mixing does not determine the $\mathrm{PCO}_{2}$.

Byrick determined the $\mathrm{CO}_{2}$ load in anaesthetized subjects by measuring the $\mathrm{CO}_{2}$ concentration at the tip of the tracheal tube and the inspiratory flow rate. ${ }^{6}$ Some of our computed $\mathrm{CO}_{2}$ loads (Table, lines 2 to 7 ) agree well 


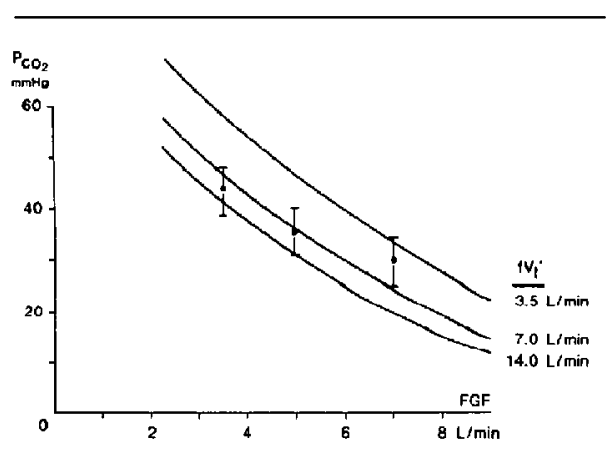

FIGURE 5 Comparison of computed data (lines) with experimental results from reference 3 .

with these measurements. They also add information concerning those factors that determine the $\mathrm{CO}_{2}$ load. The comparison, however, is made difficult because $\mathrm{f}, \mathrm{VT}$, and $\mathrm{VCO}_{2}$ are not known for the clinical data and because our idealized definition of $\mathrm{CO}_{2}$ load assumes a measurement of $\mathrm{FCO}_{2}$ at the "entrance" of alveoli.

Even though the mathematical derivation of the theory is straightforward, it is difficult to see clearly how the various factors and steps combine to determine a particular effect. The following relationship may be helpful in clarification. It is based on the concept of the functional dead space of the Bain circuit and on the simplifying assumption that flow rate during both inspiration and expiration follows a square wave pattern. The $\mathrm{CO}_{2}$ profile (Figure 2) becomes rectangular. The functional dead space is then equal to

$V_{D b}=\left(V T^{\prime}-V_{D a n}\right)\left[f T_{T}^{\prime} /\left(f V T^{\prime}+F G F\right)\right]($ Equation 3)

The relationship shows that the dead space effect of the Bain circuit is dependent on the set ventilation ( $\left[, \mathrm{VT}^{\prime}\right)$ and on FGF. The equation illustrates the clinical observation that an increase of FGF reduces $\mathrm{PCO}_{2}$ mure than an increase of $\mathrm{VT}^{\prime}$. Indeed, $\mathrm{FGF}$ and ventilation have opposite effects on $V_{D t}$ : when FGF is raised, $Y_{D h}$ is markedly reduced and $\mathrm{PCO}_{2}$ declines. When, however, $\mathrm{Vr}^{\prime}$ is raised, rebreathing and $\mathrm{VDb}_{\mathrm{Db}}$ both increase. The effect on gas exchange becomes clear if the alveolar ventilation with the circle system $\left(V_{A}=V_{T}-V_{D a n}\right)$ is compared to the alveolar ventilation obtained with a Bain circuit $\left(V_{A}=V_{T}-V_{D a n}-V_{D}\right)$. While the classical alveolar gas definition shows how $V_{A}$ increases markedly when $V_{T}$ is raised, $V_{A}$ can rise only moderately in the Bain circuit since any increase of VT is accompanied by an increase of $\mathrm{VDb}$

Equation 3 also includes the subject's anatomical dead space, which is subtracted from $\mathrm{V}_{\mathrm{T}^{\prime}}$. This subtraction, obviously, reduces the functional dead space and points out a unique feature of the Bain circuit which is elaborated in the Appendix. The subject's dead space contains $\mathrm{CO}_{2}$ at the end of an inspiration which is eliminated as the next breath. This $\mathrm{CO}_{2}$ does not contribute to the metabolic $\mathrm{CO}_{2}$ load to the subject and has therefore to be subtracted from the $\mathrm{CO}_{2}$ rebreathed. The subtraction is the major reason why the degree of rebreathing is as low as it is with the Bain circuit and why therefore FGF can be set at a level not much higher than the total ventilation of the subject without causing a substantial increase of $\mathrm{PCO}_{2}$.

The theory is helpful in making clinical adjustments and decisions. It points to similarities and differences between the Bain circuit and the circle system. The two systems are alike in that the $\mathrm{PCO}_{2}$ of the patient is proportional to $\mathrm{VCO}_{2}$ - This finding was confirmed in experiments with the bench model. It allows us to adjust any set of data given in this paper (Table, Figures) to conditions in an assumed patient with a $\dot{V C O}_{2}$ different from the value chosen in the Table $\left(\mathrm{VCO}_{2}=0.26 \mathrm{~L} \cdot \mathrm{min}^{-1}\right)$. It allows us to predict the metabolic effect of the Bain circuit in patients of different weight. The theory, however, also points to features particular to the Bain circuit. Let us assume, for example, two patients weighing 70 and $35 \mathrm{~kg}$, respectively. The $\mathrm{CO}_{2}$ productions of the two subjects are assumed to be 0.26 and $0.13 \mathrm{~L} \cdot \mathrm{min}^{-1}$. The $\mathrm{PCO}_{2}$ of the first patient is estimated to be about $40 \mathrm{mmHg}$ if the ventilation is set as in the Table, line 2 . If we reduce the FGF for the second patient to $3.5 \mathrm{~L} \cdot \mathrm{min}^{-1}$ to account for the weight difference, the theory predicts a $\mathrm{PCO}_{2}$ of $35 \mathrm{mmHg}$ (Table, line 8 ; the $\mathrm{PCO}_{2}$ in line 8 is divided by 2 because of the patient's low $\mathrm{VCO}_{2}$ ). If, however, the VT of the second subject is alsa lowered by 50 per cent, the $\mathrm{PCO}_{2}$ may now be expected to rise to $47 \mathrm{mmHg}$ (Table, line 9). The theory thus justifies a clinical rule which distinguishes Bain and circle system adjustments: the main adjustment in the circle system is ventilation ( $\mathrm{fVr}$ ) while the main adjustment in the Bain system is the FGF. The equations may, presumably, be extended for use in children. Computations may be attempted using the approach outlined in the Appendix.

On theoretical grounds onc may cxpect the respiratory quotient to influence rebreathing. Indeed, a $R Q$ of less than unity $(0.7)$ recuces the expired volume and may increase rebreathing by about one per cent, an insignificant change. The uptake of anaesthetics, however, may have a more profound effect. The uptake of $\mathrm{N}_{2} \mathrm{O}$, in particular, may reach a rate of $1 \mathrm{~L} \cdot \mathrm{min}^{-1}$ during anesthetic induction. Computations indicate that this would increase $V D b$ by about 26 per cent and $\mathrm{PACO}_{2}$ by about 14 per cent. Such an increase is perhaps clinically not striking but may lead to interesting observations.

In summary, a theory is offered and substantiated with 
bench model data which offers useful insight into how the different settings controlled by the physician affect the gas exchange of a subject connected to the Bain circuit. Some simple rules which are standard clinical practice are rationalized. The improved understanding may further extend the use of the Bain circuit.

\section{Acknowledgements}

The authors thank Dominic Jaeger for deriving Equation 13 and Sem Lampotang, Huib van Genderigen, and Drs. Joachim S. Gravenstein and J.E.W. Beneken for critically reading the manuscript.

\begin{abstract}
Appendix
In order to assess mathematically the effect of rebreathing on a subject using a Bain circuit, one has to account for the gas volumes going into and out of the respiratory system and for the $\mathrm{CO}_{2}$ being eliminated and rebreathed. The $\mathrm{O}_{2}$ exchange may be assessed along the same lines. The tidal volume taken in by the subject is larger than the tidal volume read off the ventilator since fresh gas enters the system between subject and ventilator. If the subject's tidal volume is $V_{T}$ and the volume displacement of the ventilator $V \tau^{\prime}$, we may write for inspiration:
\end{abstract}

$V_{T}=V_{T^{\prime}}+F G F \times T_{i}$

(Equation 4)

where $T_{i}$ is the time of inspiration. This equation defines two sources of inspired gas: $V T^{\prime}$ comes from the expired limb and contains $\mathrm{CO}_{2}$, FGF $\times \mathrm{T}_{i}$ comes from the fresh gas source and is $\mathrm{CO}_{2}$ free. Before going on to compute the $\mathrm{CO}_{2}$ rebreathed, i.c., the $\mathrm{CO}_{2}$ contained in $\mathrm{VT}^{\prime}$, it is useful to define two preliminary equations.

The identity of Equation 4 may also be expressed in terms of gas flows: the instantaneous flow in the airways, $\dot{V}_{i}$, is the sum of the flow coming from the expired limb $\dot{V}_{i}^{\prime}$ plus the fresh gas flow

$\dot{\mathrm{V}}_{\mathrm{i}}=\mathrm{dV}_{\mathrm{i}} / \mathrm{dt}=\dot{\mathrm{V}}_{\mathrm{i}}{ }^{\prime}+\mathrm{FGF}$

(Equation 5)

Similarly, for expiration, the flow in the expired limb $\dot{V}_{\mathrm{o}}^{\prime}$ equals the sum of the expired gas flow $\dot{V}_{\mathrm{e}}$ plus fresh gas

$\dot{V}_{\mathrm{e}}^{\prime}=\mathrm{dV}_{\mathrm{e}}{ }^{\prime} / \mathrm{dt}=\dot{\mathrm{V}}_{\mathrm{e}}+\mathrm{FGF}$

(Equation 6)

In order to determine the amount of $\mathrm{CO}_{2}$ rebreathed, we need to compute the $\mathrm{CO}_{2}$ content (in $\mathrm{ml}$ ) of $\mathrm{VT}^{\prime}$. If the concentration of $\mathrm{CO}_{2}$ in the expired limb were constant along the tube, the $\mathrm{CO}_{2}$ load would equal $\mathrm{VT}_{\mathbf{T}}$ times that concentration. Unfortunately, the $\mathrm{CO}_{2}$ concentration is only constant when $\dot{V}_{c}$ is a square wave and the determination of the $\mathrm{CO}_{2}$ load requires a tedious integration which takes two steps. First, we compute the concentration of $\mathrm{CO}_{2}$ which results from the mixing of expired gas with fresh gas; second, we determine how much of the gas blown into the expired limb is rebreathed and how much $\mathrm{CO}_{2}$ the rebreathed gas contains. Figure 2 gives an example of $\mathrm{COO}_{2}$ profile in the expired limb. The figure plots the $\mathrm{FCO}_{2}$ at any given site along the tube $\left(\mathrm{FBCO}_{2}\right)$ against the volume of the tube up to that site. The amount of rebreathed $\mathrm{CO}_{2}$ per breath is the area under the profile up to volume $V \mathrm{~T}^{\prime}$ or

$\mathrm{CO}_{2}$ rebreathed $=\int_{0}^{\mathrm{VT}^{\prime}} \mathrm{FuCO}_{2} \mathrm{dV}_{e}^{\prime}$

(Equation 7)

Not all the $\mathrm{CO}_{2}$ rebreathed, however, reaches the alveolar space and therefore affects the metabolism. Some $\mathrm{CO}_{2}$ which, at the end of our inspiration, is located in the anatomical dead space is blown out again as the first aliquot of the expirate. That aliquot is usually not rebreathed since it reaches the distal end of the cxpircd limb. This is a unique feature of the Bain circuit. In other circuits, the anatomical and the equipment dead space is usually filled with fresh air at the end on an inspiration, and the first gas to be expired is $\mathrm{CO}_{2}$ free. The aliquot of $\mathrm{CO}_{2}$ which is rebreathed but does not reach the alveoli is proportional to $V_{\text {Dan }}$ multiplied by a factor which takes the dilution with fresh air into account $\left(\left(\dot{V}_{i}-F G F\right) / \dot{V}_{i}\right)$. To obtain the metabolic $\mathrm{CO}_{2}$ load, Equation 7 needs therefore to be integrated to $V_{\mathbf{T}}^{\prime}$ minus $V_{D a n}\left(\dot{V}_{i}-F G F\right) / \dot{V}_{i}=$ VDan':

metabolic $\mathrm{CO}_{2}$ load $=\int_{0}^{\mathrm{VT}^{\circ}-\mathrm{V}^{\circ}{ }^{\circ}} \mathrm{FBCO}_{2} \mathrm{dV}_{\mathrm{e}^{\prime}}$

(Equation 8)

This integration requires same algebraic manipulation since the variation of $\mathrm{FBCO}_{2}$ is known as a function of time (Equation 1) but not as a function of expired volume (Equation 8). Replacing in Equation $8 \mathrm{FBCO}_{2}$ and dV $\mathrm{d}_{\mathrm{e}}$ by their time functions (Equations 1 and 6, respectively) we obtain

metabolic $\mathrm{CO}_{2}$ load $=\int_{0}^{t^{\prime}} \mathrm{FACO}_{2} \frac{\dot{\mathrm{V}}_{\mathrm{e}}}{\left(\dot{\mathrm{V}}_{\mathrm{c}}+\mathrm{FGF}\right)}$

$$
\times\left(\dot{V}_{e}+F G F\right) d t
$$

which easily simplifies. $\mathrm{FACO}_{2}$ is unknown, but is assumed to be a constant at steady state:

metabolic $\mathrm{CO}_{2}$ load $=\mathrm{FACO}_{2} \int_{0}^{\mathrm{t}^{\prime}} \dot{\mathrm{V}}_{\mathrm{e}} \mathrm{dt} \quad$ (Equation 9)

Equation 9 is useful in showing what variables determine the $\mathrm{CO}_{2}$ load. Unfortunately, it includes $\mathrm{FACO}_{2}$ which is the unknown we are trying to determine. The way out of the circular argument is found by introducing the notion of dead space. If we express the $\mathrm{CO}_{2}$ load by its equivalent dead space, which is the dead space which would result in the same load $\left(\mathrm{CO}_{2}\right.$ load $\left.=\mathrm{FACO}_{2} \times \mathrm{VD}\right), \mathrm{FACO}_{2}$ 
cancels and we obtain the following relationship defining the functional dead space of the Bain circuit:

$V_{D b}=\int_{0}^{t^{t}} \dot{V}_{\mathrm{e}} \mathrm{dt}$

(Equation 10)

The metabolic effect of the Bain circuit becomes a "simple matter" of an additional dead space which is added to the anatomical dead space in the standard alveolar gas equation according to

$\mathrm{FACO}_{2}=\dot{V} \mathrm{CO}_{2} / \mathrm{f}\left(\mathrm{VI}_{\mathrm{I}}-\mathrm{VDan}_{\mathrm{Da}}-\mathrm{VDb}\right) \quad$ (Equation 1I)

The boundary conditions for Equation 10 are given by the time $t^{\prime}$ needed for the gas that enters the Bain circuit to reach a volume equal to $V_{T^{\prime}}-V_{D a n}$ (see Equation 8 ).

The dead space of the Bain circuit is not a volume within the breathing circuit (it is, e.g., not identical to the volume of the expired limb). It is, instead, a functional space which depends on the flow pattern and on FGF. In a given subject or patient it depends on $\mathrm{f}, \mathrm{VT}, \mathrm{FGF}$ and the wave form.

Examples may illustrate the computation. Let us assume that $\mathrm{f}=10 \mathrm{bpm}=0.166 \mathrm{bps}, \mathrm{VT}=0.75 \mathrm{~L}, \mathrm{FGF}=$ $7 \mathrm{~L} \cdot \mathrm{min}^{-1}=0.116 \mathrm{~L} / \mathrm{sec}, \mathrm{I}: \mathrm{E}=1: 2$. Inspiration is a square wave with $\dot{\mathrm{V}}_{\mathrm{i}}=\mathrm{V}_{\mathrm{T}} / \mathrm{T}_{\mathrm{i}}=0.75 / 2=0.375 \mathrm{~L} / \mathrm{sec}$. $\mathrm{T}_{\mathrm{e}}$ is $4 \mathrm{sec}$ and $\mathrm{VT}^{\prime}=0.518 \mathrm{~L}$ (Equation 4). We further mimic the expiratory flow curve with

$\dot{\mathrm{V}}_{\mathrm{c}}=\mathrm{K}\left(\mathrm{e}^{\mathrm{it}-\mathrm{Te}) ; 0.6}-\mathrm{e}^{(\mathrm{t}-\mathrm{Te}) / 0.3}\right)$

(Equation 12)

which reaches a maximum $\left(0.63 \mathrm{~L}-\mathrm{min}^{-1}\right)$ after $0.4 \mathrm{sec}$ and then declines exponentially, leaving an expiratory pause of about $1 \mathrm{sec}$ during which expiratory flow is appreciably lower than FGF. This equation is a fair approximation of a passive expiration of a normal subject. For $\mathbf{f}=10$ and $\mathrm{VT}_{\mathrm{T}}=0.75, \mathrm{~K}$ is 2.55 . Note that t runs backwards (from $T_{e}$ to zero) in this equation, because the gas expired last is rebreathed first.

The amount of $\mathrm{CO}_{2}$ in the dead space at the end of an inspiration equals $\mathrm{FACO}_{2} \times \mathrm{VD}_{\text {an }} \times \dot{\mathrm{V}}_{\mathrm{i}}{ }^{\prime}\left(\dot{\mathrm{V}}_{\mathrm{i}}-\mathrm{FGF}\right)=$ $\mathrm{FACO}_{2} \times 0.125 \times 0.69=\mathrm{FACO}_{2} \times 0.086 \mathrm{~L}$. Thus, VDan' in Equation 8 equals $0.086 \mathrm{~L}$. This volume is subtracted from $\mathrm{VT}^{\prime}$ in order to obtain the upper limit of the integral in Equation 8. To evaluate the time $t^{\prime}$ needed to accumulate a volurne equal to $\mathrm{VT}^{\prime}-\mathrm{V}_{\mathrm{Dan}^{\prime}}=0.518-$ $0.086=0.432 \mathrm{~L}$ we use Equation 6

$\int_{0}^{1^{\prime}}\left(\dot{V}_{\mathrm{e}}+\mathrm{FGF}\right) \mathrm{dt}=0.432 \quad$ with $\mathrm{t}^{\prime}=2.57 \mathrm{sec}$

We now integrate Equation 10 from $t=0$ to $t^{\prime}=2.57$ and find $V_{D b}=0.132 \mathrm{~L}$. This value is entered together with $V_{\text {an }}=125 \mathrm{ml}$ into the alveolar gas equation (Equation 11) to obtain $\mathrm{FACO}_{2}$ - In the bench model $\mathrm{VCO}_{2}$ was $0.26 \mathrm{~L}-\mathrm{min}^{-1}$ and $\mathrm{FACO}_{2}$ becomes $0.053 . \mathrm{PACO}_{2}$ in the bench model is computed for ATPD conditions, assuming that gas in the model is dry and is found to be $40 \mathrm{mmHg}$.

The metabolic effect of the Bain circuit may be computed in a similar way when the flow curve is assumed to follow a sinusoidal course $\left(\dot{V}=\dot{V}_{\max } \sin 2 \pi \mathrm{ft}\right)$. The approach is as outlined above. Rebreathing does not start immediately with inspiration; it takes a short time $t_{1}$ for $\dot{V}_{i}$ to reach a leve $]$ equal to FGF $\left(t_{1}=\left(\sin ^{-1}\left(\mathrm{FGF} / \dot{V}_{\max }\right)\right) /\right.$ $2 \pi f$ ). Similarly it takes a short amount of time $t_{2}$ for $\dot{V}$ to reach zero after it has declined again to a value equal to FGF.

$V T^{\prime}=\int_{t_{1}}^{t_{z}}\left(\dot{V}_{\max } \sin 2 \pi f t-F G F\right) d t$

(Equation 13)

$V T^{\prime}$ is found to equal $0.436 \mathrm{~L}$. $V D b$ is found to equal $0.217 \mathrm{~L}$. Borh values are slightly different from those ubtained for the square/exponential curve.

The equations presented allow us to determine the effect of changes of $\mathrm{RQ}$ on the gas exchange. A simple example is that of $\mathrm{N}_{2} \mathrm{O}$ anaesthesia. $\mathrm{N}_{2} \mathrm{O}$ uptake will increase inspiratory tidal volume and therefore $\mathrm{VT}^{\prime}$. If $\mathrm{VT}^{\prime}$ increases, the metabolic $\mathrm{CO}_{2}$ load (Equation 8) increases and so does the functional dead space (Equation 10). For $\mathrm{N}_{2} \mathrm{O}=1 \mathrm{~L} \cdot \mathrm{min}^{-1}$ or $100 \mathrm{ml} /$ breath $V_{T^{\prime}}$ would increase from 0.518 to $0.618 \mathrm{~L}$ and $V_{D b}$ from 0.132 to $0.194 \mathrm{~L}$ using the above procedure.

The computation of $V_{D b}$ is simplified if we assume that inspiration and expiration follow a square wave pattern and if $T_{i}=T_{c}=\frac{1}{2} f$. Substituting $\dot{V}_{e}=V_{T} / T_{e}$ in Equation 1, we obtain for $\mathrm{FBCO}_{2}$ the term $\mathrm{FACO}_{2} \times 2 \mathrm{fVT} /(2 \mathrm{fVT}+$ FGF). Similarly we obtain in inspiration $\mathrm{FICO}_{2}=\mathrm{FBCO}_{2}$ $\times 2 \mathrm{fVT}^{\prime} /\left(2 \mathrm{fVT}^{\prime}+\mathrm{FGF}\right)$. The $\mathrm{CO}_{2}$ rebreathed becomes $\mathrm{VT}^{\prime} \mathrm{FICO}_{2}$. To obtain the amount of $\mathrm{CO}_{2}$ that reaches the alveoli per breath we compute VDan' as before and we get after some algebra

$V_{D b}=\left(V T^{\prime}-V_{D a n}\right)\left[\left(f V T^{\prime}\right) /\left(f V T^{\prime}+F G F\right)\right]$

(Equation 3)

This equation yields, despite its assumption of a square wave pattern of breathing, a very good estimate of the $\mathrm{PCO}_{2}$ in a model and in patients. Assuming, e.g., the same conditions as in the Table, line 2, Equation 3 yields a $\mathrm{PCO}_{2}$ of $37.5 \mathrm{mmHg}$ as compared to $40 \mathrm{mmHg}$ for the elaborate integration procedure. 


\section{References}

I Mapleson WW. Elimination of rebreathing in various semiclosed anaesthetic systems. Br J Anaesth 1954; 26 323-32.

2 Bain JA, Spoerel WE. A streamlined anaesthetic system. Can Anaesth Soc J 1972; 19: 426-35.

3 Bain JA, Spoerel WE. Prediction of arterial $\mathrm{CO}_{2}$ tension during controlled ventilation with a modified Mapleson D system. Can Anaesth Soc J 1975; 22: 34-8.

4 Mapleson $W W$. Theoretical considerations of the effects of rebreathing in two semiclosed anaesthetic systems. Br Med Butl 1958; 14: 64-8.

5 Rose DK, Byrick RI, Froese $\mathrm{AB}, \mathrm{CO}_{2}$ elimination during spontancous ventilation with a modified Mapleson D system. Can Anaesth Soc J 1978; 25: 353-65.

6 Byrick RJ. Respiratory compensation during spontaneous ventilation with the Bain circuit. Can Anaesth Soc J 1980; 27: 96-105.

7 Gravenctein $N$, Lampotang $S$, Beneken JEW. Factors influencing capnography in the Bain circuit. J Clin Monit $1985 ; 1: 6-10$.

\section{Rèsumé}

Ceci est une analyse théorique et expérimentale du circuit Mapleson $D$ (Bain). Un test était utilisé afin de dêterminer les effets de la fréquence respiratoire, volume courant, et fiot de gaz frais sur la composition du gaz alvéolaire quand un circuit commercial est utilisé. En plus un effort est fait afin de dëriver les équations mathématiques qui decriven le profil du $\mathrm{CO}_{2}$ dans la partie expiratoire du circuil de Bain, la quantile de $\mathrm{CO}_{2}$ réinspiré, et l'effet de cette réinspiration sur la composition du gaz alvéolaire. Les données obtemues de ce test ainsi que les équations ont été comparées aux données de la littérature. L'effer du circuit de Bain sur l'echange gazeux est comparé $d$ celui avec un espace mort équivalent. 